\title{
PROPOSED INTEGRATED BICYCLE FEEDER MODE SERVICE ANALYSIS FOR BUS RAPID TRANSIT SYSTEM- A MULTINOMIAL LOGIT MODEL APPROACH
}

\author{
Manjurali I. Balya', Rakesh Kumar' \\ ${ }^{1,2}$ Sardar Vallabhbhai National Institute of Technology, Surat, Gujarat, India
}

Received 12 May 2016; accepted 29 December 2016

\begin{abstract}
Public transit plays a vital role in economic development for access to the commuters/ travelers to the city centers of metropolitan cities of developing countries. Accessibility of public transit system is a prime factor faced by developing countries due to the lack of feeder services. Therefore, an attempt to improve the feeder services (with different modes i.e. as walking, bicycle, mini bus) is major importance. The present research focuses on new innovative ideas of bicycle as feeder mode with its three services i.e. Exclusive Bicycle Lane, Bicycle operation in mixed traffic with park \& ride facility and Bicycle Sharing Service for Bus Rapid Transit System (BRTS) corridor of Ahmedabad city. The multinomial logit model was applied to develop the models. The findings from the study revealed that as income increases the preference to BMT-PR service increases over BSS and EBL service for their commuting purpose. The observations of age distribution shows with increase in age, the choice of EBL service over BSS and decrease BMT-PR service over BSS. Gender wise distribution indicated that preference to EBL service as well as BMT-PR service are higher among male groups compared with female groups. The observation of the study revealed that with increase in travel time, the respondents are more preferring BSS service over both EBL service and BMT$\mathrm{PR}$ service. Same as travel distance increases will be more preference of BSS over EBL service and BMT-PR service by commuters. The output of this research can be extremely useful to increase ridership of public transit by integrating feeder service.
\end{abstract}

Keywords: Integrated bicycle feeder mode service (IBFMS), bicycle feeder mode, Socioeconomic Characteristics, multinomial logistic regression.

\section{Introduction}

Due to the lack of accessibility to the bus transit stop often the users prevents a large section of society from using the bus in developing countries. This problem professed as the unavailability of access/ egress transport connectivity to the transit stop. Accessibility using walking and biking to transit stop can often solve the problem of first/last mile connectivity (Chandra et al., 2013). Most of the research focused on the absolute access and egress distance with less attention placed on the share of access and egress to total trip distance or time (Krygsman et al., 2004). The integrated feeder service can be beneficiated to society for reducing the accessibility problems.

${ }^{1}$ Corresponding author: mibalya.civil@spcevng.ac.in 
Walking and biking are favorable modes if the built environment around the stop is contributing to for these modes and over the years. These two methods have seen a good amount of popularity relatively due to health benefits associated with them (Replogle, 1992).

The present research paper has mainly focused on proposed integrated bicycle feeder service for Bus Rapid Transit System for Ahmedabad city. Feeder bicycle mode is an accessible, low cost, non polluting and healthy mode of travel and it improves the health, reduce green house gas emissions \& dependency on fuels (Advani and Tiwari, 2006; Balya and Rakeshkumar, 2016) . Bicycle provides the extension of the catchment areas of transit stops far beyond the walking range with lower cost than other modes for public transport (Pucher and Buehler, 2009).

Cycling integration is one of the most efficient transports for users that can be helpful in health prospective. It is eco-friendly for environment, reduce congestion, etc. (Advani and Tiwari, 2006) showed that bicycle is an accessible, lowcost, non-polluting and healthy mode of travel, and we need to encourage lifestyle changes that improve our health, reduce greenhouse gas emissions and our dependence on fossil fuel. (Replogle, 1992) discusses that bicycles are the fastest growing and predominant mode of access to express public transportation services in many countries. Coordinating bicycling with public transport is mutually beneficial, enhancing the benefits of modes and encouraging more bicycling as well as more public transport use (Brons et al., 2009; Givoni and Rietveld, 2007; Hegger, 2007; Pucher and Buehler, 2009). Over longer distances, using the bicycle as a feeder mode for public transit can result in shorter trip times than a point-to-point bicycle trip, despite the delay while waiting a train to arrive (Advani and Tiwari 2006).

This paper aimed at investigating the development of models for proposed integrated bicycle feeder mode service using Multinomial Logit (MNL) model in Viratnagar to Naroda Patiya BRTS corridor of Ahmedabad city. The three models are developed to analyze the choice of the respondents towards bicycle feeder services and its influence on ridership of BRTS. The model results would identify the probability of an overall selection of the peoples for feeder facilities that could use as an input for future travel demand forecasting for BRTS of Ahmedabad City.

\section{Integrated Bicycle Feeder Network}

The integrated bicycle network has developed based upon the bicycle taken as feeder mode with three service categories viz. exclusive bicycle lane, bicycle operation in mixed traffic with park and ride facility and bicycle sharing service. The BRT service at origin and destination both ends are linked with integrated bicycle feeder services shown in Fig. 1. These services particularly provided at access and egress trips only. Here this paper is on the basis of case study only. 

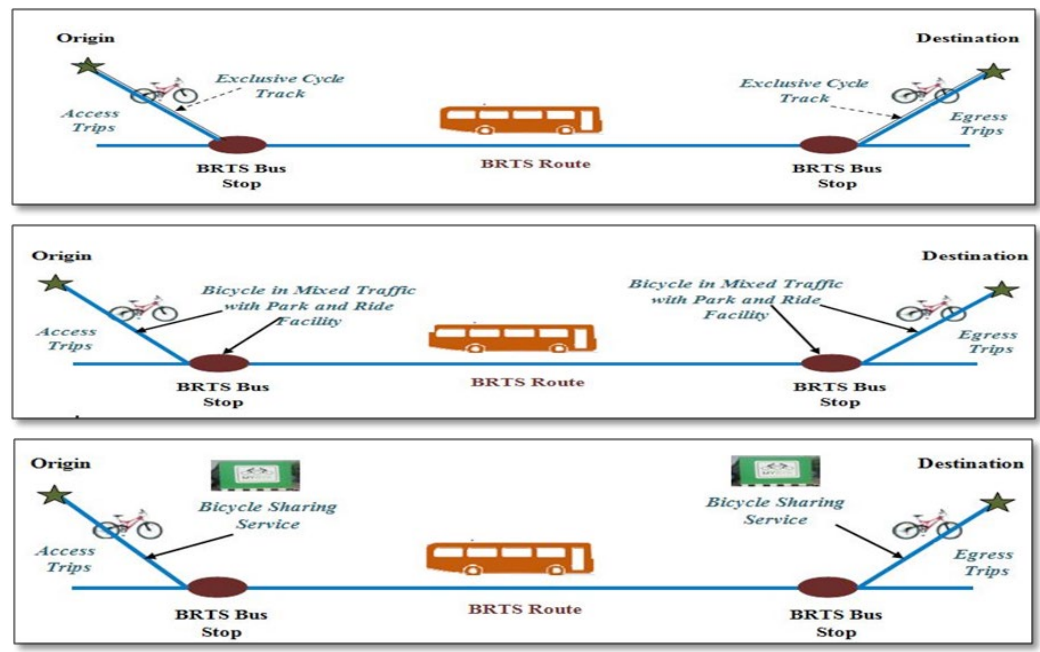

Fig. 1.

Integrated bicycle feeder service network for public transit service (Balya and Kumar, 2016)

\section{Representative Area and Data Description}

\subsection{Description of the Study Area}

Ahmedabad, which is the largest Metropolitan city of Gujarat in India, is selected for this study. This city had a population of 5.5 million as per census 2011 with the population density of $466 \mathrm{Sq}$. $\mathrm{Km}$. The city had divided with six different zones i.e. North, South, East, Central, West and New West. In the city of Ahmedabad, our case study area corridor of Viratnagar to Naroda Patiya is falling under two zone's name as East Zone and North Zone. The ward-wise distribution of the survey area are Bapunagar, Rakhiyal, Nikol falling in East Zone and Asarwa, Naroda Road, Saraspur, Potaliya, Kubernagar, Saijpur, Thakkarnagar, Naroda Muthiya are falling under North Zone. As per the census 2011, the population of the Case study area is 0.94 Million with a total area of $30.98 \mathrm{Sq} . \mathrm{km}$. The description of the study area is shown in Fig. 2. (Balya and Kumar, 2016).
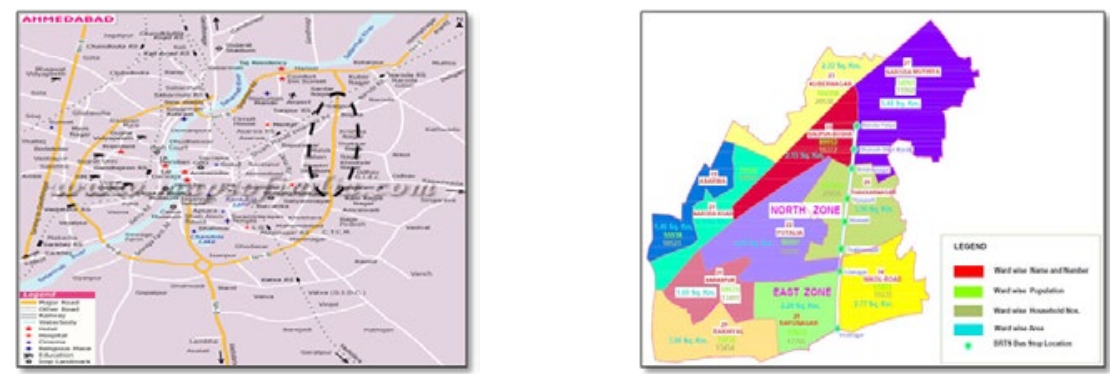

Fig. 2.

Study Area Corridor-Maninagar to Naroda Patiya (Ahmedabad) 


\subsection{Data Description}

The primary data source used for this analysis is a Home Interview Survey conducted in the representative study area BRTS corridor Viratnagar to Naroda of Ahmedabad city. The Surveys conducted by eight members' team (Undergraduate students) who knocked on doors during various times of the day and done in person interviews. The questionnaire prepared as per standard literature basis.

The questions were structured based on significance to the respondents' experiences and trips information. This questionnaire comprises of the revealed preference data such as description of trips (such as, travel mode, purpose of trip, origin \& destination), travel time, travel cost and travel distance, the features of travelers (includes, age, gender, monthly income, occupation, vehicle ownership, and level of education), and travel behavior. Details on the response of the people towards the bicycle as a feeder mode for the bus transit system have also acquired.

The questions that address opinions towards bicycle as a feeder mode for bus transit system of respondents were included only in the Stated Preference Survey and associated with demographic, socioeconomic and trip characteristics. The participants were requested to tell their preferable choice from three variables on Likert scales measurement, by responding to a set of questions. The survey information incorporated socioeconomic status and trip information of respondents, and perceptions of respondents towards bicycle feeder services for Bus Rapid Transit System. According to Indian Census, 5\% margin of error and for $95 \%$ confidence level, the minimum sample size was found to be approximately 1040 by Cochran formula. We thus collected 1040 home interview surveys for our analyses.

\subsection{Preliminary Data Analysis}

A preliminary analysis of the coded data was performed to yield an analysis of integration of bicycle as feeder mode of commuters in the case study of BRTS corridor of Ahmedabad city. Various cross-classification charts were prepared with respect to income distribution, age, vehicle ownership etc. The analyzed results are explained in the following sections.

The socioeconomic factors such as monthly income, vehicle ownership and household size are noticeably major factors of the socioeconomic characteristics. The data analysis revealed that the Rs. $<10000$ people are as $41 \%$ while $24 \%$ are falls under Rs. $10001-20000$ category. Nearly $35 \%$ people have their income more than Rs. 20000 as per analysis. The vehicle ownership result shows that $15 \%$ people have their own car whereas $36 \%$ of people have $2 \mathrm{~W}$ which highest proportion of vehicle ownership. $22 \%$ people have bicycle whereas $27 \%$ have no vehicle which falls in under economically weaker sections and low income groups. As per the survey, the household size observed as $29 \%$ households have 6 members per household while $24 \%$ have 5 members per households. Travel time analysis revealed that $33 \%$ people are travelling daily up to $31-45$ minutes while $24 \%$ respondents are daily travels to 60-90 minutes. Nearly $7 \%$ people are daily travel more than 90 minutes while $13 \%$ people are travel less than 15 minutes per day. Travel distance related questionnaire revealed that $33 \%$ respondents have 5 to $10 \mathrm{~km}$ travel distance whereas $28 \%$ 
people have 2 to $5 \mathrm{~km}$ travel distance per day. It is observed that $7 \%$ people have $1 \mathrm{~km}$ whereas $11 \%$ have more than $15 \mathrm{~km}$ travel distance for daily.

\section{Model Specification}

The following variables were considered for analysing integration of bicycle as feeder mode for BRTS corridor in the city of Ahmedabad.

The socioeconomic and travel parameters were assessed as follows: The mean value of income was assessed and assembles on an ordinal scale from 1 to 6 (INR $<10000$, 10001-20000, 20001-30000, 30001-40000, 40001-50000, >50000). Similarly, the vehicle ownership climbed from 1 to 4 as (2W, Car, Bicycle and No Vehicle) and Household Size scale from 1 to $7(1,2,3$, 4, 5, 6 and 7). The Total Travel Time (TT) (access time + in vehicle time+ egress time) divided on the scale as from 1 to 6 (0-15 min., 15-30 min., 30-45 min., 45-60 min., 60-90 min., and $>90 \mathrm{~min}$.). The travel distance added with access range + in vehicle distance + egress distance with six categories from 1 to $6(<1 \mathrm{~km}, 1-2 \mathrm{~km}, 2-5 \mathrm{~km}, 5-10 \mathrm{~km}$, $10-15 \mathrm{~km}$ and $>15 \mathrm{~km})$.

The attitudinal variables were categorised as follows: The three response variables (dependent variables) such as Exclusive Bicycle Track (EBL), Bicycle Operation in Mixed Traffic with Park \& Ride Facility (BMT-PR) and Bicycle Sharing Service (BSS) are categorized. Hence, these measured on Likert scales i.e. accept or reject the service. The independent (predictors) variables were categorized as income, gender, household size, age, vehicle ownership, travel time, travel cost and travel distance. The impact and the effect of these variables on the response variables are found out in this model. The variables represented in coding system of Statistical Package for Social Science (SPSS) version 16.0 software for the present study.

\section{Results and Discussion}

Multinomial Logit (MNL) model was carried out to identify the influence of various factors on the attitudinal behavior of the commuters towards proposed integrated bicycle feeder services. The idea to develop this model was to identify the choice of public transit users from the case study area and to catch the people from the farther away residential area towards the nearest public transit bus stops to increase the ridership of public transit through proposed feeder service. The impact will be a reduction of the private usage of vehicles which will result in a reduction of congestion, pollution and control accidents. All the variables obtained and presented had significant parameter estimates and logical signs.

When using MNL regression model, one category of the dependent variable is selected as the reference category (here 'Bicycle Sharing Service' considered as reference category). All the parameters in the model are inputted concerning this category. It can call as a standard or reference category to which others (response category) would be compared logically. The coefficients are estimated through maximum likelihood method. Odds ratios are determined for all independent variables for each class of the dependent variable except the reference category. Odds ratio represents the change in the odds of being in the dependent variable category versus the reference category related to a one-unit shift in the independent variable. 
The Likelihood ratio test indicates the contribution of the variables to the overall relationship between the dependent variables and independent variable in distinguishing between the sets specified by the dependent variable. The result shows that all the variables have significance less than 0.05 . So, it can be observed that all the variables have significant contribution towards prediction of bicycle feeder mode services. The contribution of each variable to the model is explained by likelihood ratio test as shown in Table 1.

Table 1

Likelihood Ratio Tests

\begin{tabular}{|c|c|c|c|c|}
\hline \multirow{2}{*}{ Effect } & Model Fitting Criteria & \multicolumn{2}{|c|}{ Likelihood Ratio Tests } \\
\cline { 2 - 5 } & $\mathbf{- 2 \text { Log Likelihood of Reduced Model }}$ & Chi-Square & df & \multicolumn{2}{c|}{ Sig. } \\
\hline Intercept & 2.15113 & 72.876 & 2 & 0.000 \\
\hline Income & 2.08803 & 9.756 & 2 & 0.012 \\
\hline Gender & 1.87153 & 1.643 & 2 & 0.440 \\
\hline HHS & 2.07933 & 3.923 & 2 & 0.047 \\
\hline Age & 1.97603 & 1.605 & 2 & 0.076 \\
\hline VO & 2.08123 & 7.182 & 2 & 0.026 \\
\hline TT & 2.08313 & 43.272 & 2 & 0.009 \\
\hline TD & 2.22163 & 62.221 & 2 & 0.000 \\
\hline
\end{tabular}

The Pseudo $\mathrm{R}^{2}$ value indicates the proportion of variance of the response variable explained by the predictors (Ashalatha et al., 2012). The Cox and Snell $\mathrm{R}^{2}$ measure drives like $\mathrm{R}^{2}$, with higher values indicating greater model fit. The Cox and Snell $\mathrm{R}^{2}$ (Ashalatha et al., 2012; Miskeen et al., 2013) for this study are 0.763 , which indicates that model explains $76.3 \%$ of the variation in the dependent variables. Nagelkerke's result measures relied for indicating the strength of the relationship between variables. The Nagelkerke $\mathrm{R}^{2}$ for the present study is 0.596 , which suggests that the model explains roughly $59.6 \%$ of the variation in the outcome. While, the McFadden $\mathrm{R}^{2}$ value is 0.510 which state $51.0 \%$ variation in the outcome. So, finally based on the $\mathrm{R}^{2}$ value it can be concluded that the model explains nearly $51-76 \%$ variation in the study that is considered statistically significant result. The estimated summary of Pseudo $\mathrm{R}^{2}$ is presented in Table 2 .

Table 2

Pseudo R-Square

\begin{tabular}{|c|c|}
\hline Cox and Snell & 0.763 \\
\hline Nagelkerke & 0.596 \\
\hline McFadden & 0.510 \\
\hline
\end{tabular}

The parameter estimates of each predictor for commuters' choice EBL to BSS and BMT$\mathrm{PR}$ represented in Table 3 respectively. $\mathrm{B}$ values represent the MNL regression coefficients for the developed models. The negative value of coefficients decreases the willingness of that response category to the given reference category. In this study, the third category (here BSS) of each predictor is taken as reference by default.

The coefficients value for income per month for EBL service as well as BMT-PR service were negative as expected, entailing that 
increases in their values will increase the choice of BSS. Therefore the estimation of income coefficients revealed that high income respondents are more likely to use BMT-PR service because of extra charges of parking near the bus stops over BSS rather than EBL service for their commuting travels.

The age distribution result shows statistically significant $(P<0.05)$ which means it contributed in the choice of bicycle feeder services. The negative signs of coefficient for EBL service entails that young people are more likely to prefer EBL service rather than BSS service.

For BMT-PR service, the positive sign of coefficient illustrates that younger groups do not prefer BMT-PR service because of less safety in mixed traffic service.

Table 3

Parameter Estimates

\begin{tabular}{|c|c|c|c|c|c|c|c|c|}
\hline \multirow{2}{*}{\multicolumn{2}{|c|}{$\begin{array}{c}\text { Attitude towards Bicycle } \\
\text { Feeder Service (EBL- } \\
\text { BMTPR-BSS) }\end{array}$}} & \multirow{3}{*}{$\begin{array}{c}\text { B } \\
5.821 \\
\end{array}$} & \multirow{3}{*}{\begin{tabular}{|c} 
Std. Error \\
0.816 \\
\end{tabular}} & \multirow{3}{*}{$\begin{array}{r}\text { df } \\
1\end{array}$} & \multirow{3}{*}{$\begin{array}{l}\text { Sig. } \\
0.000 \\
\end{array}$} & \multirow{3}{*}{$\begin{array}{c}\operatorname{Exp}(\mathbf{B}) \\
-\end{array}$} & \multicolumn{2}{|c|}{$\begin{array}{c}\text { 95\% Confidence } \\
\text { Interval for } \operatorname{Exp}(B)\end{array}$} \\
\hline & & & & & & & \multirow{2}{*}{$\begin{array}{c}\text { Lower } \\
\text { Bound } \\
-\end{array}$} & \multirow{2}{*}{$\begin{array}{c}\text { Upper } \\
\text { Bound } \\
-\end{array}$} \\
\hline \multirow{8}{*}{$\begin{array}{c}\text { Exclusive } \\
\text { Bicycle Lane } \\
(\text { EBL) Service }\end{array}$} & Intercept & & & & & & & \\
\hline & Income & -0.286 & 0.102 & 1 & 0.005 & 0.751 & 0.615 & 0.918 \\
\hline & Gender & -0.117 & 0.180 & 1 & 0.016 & 0.890 & 0.625 & 1.266 \\
\hline & HHS & -0.078 & 0.115 & 1 & 0.497 & 0.925 & 0.738 & 1.159 \\
\hline & Age & -0.056 & 0.073 & 1 & 0.040 & 0.945 & 0.820 & 1.090 \\
\hline & VO & -0.107 & 0.115 & 1 & 0.002 & 0.898 & 0.716 & 1.126 \\
\hline & TT & -0.040 & 0.092 & 1 & 0.039 & 0.961 & 0.803 & 1.151 \\
\hline & TD & -1.530 & 0.161 & 1 & 0.000 & 0.217 & 0.158 & 0.297 \\
\hline \multirow{8}{*}{$\begin{array}{c}\text { Bicycle in } \\
\text { Mixed Traffic } \\
\text { with Park and } \\
\text { Ride Facility } \\
\text { (BMT-PR) } \\
\text { Service }\end{array}$} & Intercept & 4.655 & 0.707 & 1 & 0.000 & - & - & - \\
\hline & Income & -0.233 & 0.082 & 1 & 0.004 & 0.792 & 0.675 & 0.929 \\
\hline & Gender & -0.117 & 0.180 & 1 & 0.025 & 0.890 & 0.625 & 1.266 \\
\hline & HHS & 0.001 & 0.098 & 1 & 0.989 & 1.001 & 0.826 & 1.213 \\
\hline & Age & 0.020 & 0.078 & 1 & 0.029 & 1.020 & 0.876 & 1.188 \\
\hline & Vo & -0.144 & 0.097 & 1 & 0.000 & 0.865 & 0.715 & 1.047 \\
\hline & TT & -0.068 & 0.079 & 1 & 0.021 & 0.935 & 0.801 & 1.091 \\
\hline & TD & -0.775 & 0.133 & 1 & 0.000 & 0.461 & 0.355 & 0.598 \\
\hline
\end{tabular}

Models, Eq. (1) and Eq. (2):

${ }^{*} P_{E B L}=5.821-0.286($ Income $)-0.117($ Gender $)-0.078($ HHS $)-$

$-0.056($ Age $)-0.107($ D $)-0.040(T)-1.530($ D $)$

${ }^{*} P_{B M T-R}=4.665-0.233($ Income $)-0.117($ Gender $)+0.001($ HHS $)+$

$+0.020($ Age $)-0.144($ D $)-0.068(T)-0.775(D)$

${ }^{*} \mathrm{P}=$ Probability of choosing particular service

The gender category was introduced into the questionnaire to identify the distinct users of mode choice as male or female. The coefficient of this variable indicated a significant value; and the negative sign of this category for both EBL and BMT-PR with BSS indicating that male users are highly preferring the services than female users. The Vehicle Ownership distribution revealed that the respondent for EBL service have 0.90 times more chance over BSS service, whereas for BMT-PR service respondents have 0.86 chance over BSS. The coefficients of these variables for both the categories show significant results also. From the result it could be say that the vehicle ownership does not much impact on the choice of bicycle feeder services. 
The Household Size (HHS) is the most important parameters for mode choice of any urban area. Unfortunately and unexpectedly for the present study for both the dependent variables as EBL service and BMT-PR service, the coefficients shows insignificant results. This could be due to the respondents not worry about their family size for the use of the service.

The influence of travel time by a commuter over the bicycle feeder service, the MNL model indicated that the commuters have 0.96 times more chance to choose EBL service over BSS service, whereas they have 0.93 times more chance to choose BMT-PL service over BSS service. Therefore it can be supposed that travel time will significantly impact on the bicycle feeder services. Same as the travel time, the influence of travel distance by a commuter over the bicycle feeder service, the MNL model revealed that the commuters have 0.22 times more chance to choose EBL service over the BSS whereas they have 0.46 times more chance to choose BMT-PR service over BSS service. As compare with TT, the distance is less contributed in the choice of bicycle feeder services.

\section{Conclusion}

The basic objective of this research paper is to develop the opinion models for proposed integrated bicycle feeder mode service in Viratnagar to Naroda Patiya BRTS corridor of Ahmedabad city using Multinomial Logit (MNL) Model.

The pseudo R2 value of the model according to the Cox and Snell is the model explains 0.763 indicating $76.3 \%$ of the variation in the dependent variables. While Nagelkerke $\mathrm{R} 2$ is 0.596 , which suggests that the model explains roughly $59.6 \%$ of the variation in the outcome. So, finally based on the pseudo $\mathrm{R} 2$ value it can be concluded that the model explains nearly $59-76 \%$ variation in the present study which is considered statistically significant result.

Income wise comparison revealed that increasing income per month respondents are more likely to use BMT-PR service over BSS rather than EBL service for their commuting travels. The age wise distribution entailed that young people are more likely to prefer EBL service over BSS service whereas, the younger groups less likely prefer BMT-PR service because of less safety in mixed traffic service. Therefore it can be concluded that with increase in age, the choice of EBL service over BSS and decrease BMT-PR service over BSS. Gender wise distribution indicated that preference to EBL service as well as BMT-PR service are higher among male groups compared with female groups. The observations of travel time entailed that it is significantly impact on the bicycle feeder service whereas; the travel distance is less contributed in the choice of bicycle feeder services. With increase in travel time, the respondents are more preferring BSS service over both EBL service and BMT-PR service. Same as travel distance increases will be more preference of BSS over EBL service and BMT-PR service by commuters. So, policy makers must minimize the travel time and travel distance to attract more commuters to the BRTS.

The model developed by this study can also be utilized by BRTS operators, to implement the existing condition of BRTS facilities from the approximate probability of peoples to attract towards the integrated feeder facility through bicycle feeder services. Consequently, the probable opinion of 
respondents/travellers stated preference is incorporated in the model. Therefore, this model enhances the prediction of future trips for BRT System. To sum up the output of this research, the developed models is the foundation which can apply for BRT system of Ahmedabad city by the integration of bicycle feeder services to maximize the utility of this system. The operators whether government organizations or private sectors can utilize the outcomes of this research to enhance the ridership of BRTS through the integrating bicycle feeder facilities.

\section{Acknowledgement}

The authors are thankful to all the respondents for giving their valuable responses during Home Interview Survey.

\section{References}

Advani, M.; Tiwari, G. 2006. Bicycle-as a feeder mode for bus service. In Proceedings of the Velo Mondial conference: third global cycling planning conference, 1-8.

Ashalatha, R.; Manju, V.; Zacharia, A.B. 2012. Mode choice behavior of commuters in Thiruvananthapuram city, Journal of Transportation Engineering 139(5): 494-502.

Balya M.I.; Kumar, R. 2016. Integration of Bicycle as Feeder Mode in Bus Rapid Transit System, Journal of Intelligent Transportation and Urban Planning 4(1): 35-44.

Brons, M.; Givoni, M.; Rietveld, P. 2009. Access to railway stations and its potential in increasing rail use, Transportation Research Part A: Policy and Practice 43(2): 136-149.
Chandra, S.; Bari, M.E.; Devarasetty, P.C.; Vadali, S. 2013. Accessibility evaluations of feeder transit services, Transportation Research Part A: Policy and Practice 52: 47-63.

Givoni, M.; Rietveld, P. 2007. The access journey to the railway station and its role in passengers' satisfaction with rail travel, Transport Policy 14(5): 357-365.

Hegger, R. 2007. Public transport and cycling: living apart or together?, Public Transport International 56(2): 38-41.

Krygsman, S.; Dijst, M.; Arentze, T. 2004. Multimodal public transport: an analysis of travel time elements and the interconnectivity ratio, Transport Policy 11(3): 265-275.

Miskeen, A.; Manssour, A.; Mohamed Alhodairi, A.; Rahmat, R. 2013. Modeling of Intercity Transport Mode Choice Behavior in Libya: a Binary Logit Model for Business Trips by Private Car and Intercity Bus, Australian Journal of Basic \& Applied Sciences 7(1): 302-311.

Pucher, J.; Buehler, R. 2009. Integrating bicycling and public transport in North America, Journal of Public Transportation 12(3): 79-104.

Replogle, M. 1992. Bicycles and cycle-rickshaws in Asian cities: issues and strategies, Transportation Research Record 1372: 76-84. 